\title{
A Novel Design of Energy-saving Wireless Intelligent Agricultural Detecting System
}

\author{
http://dx.doi.org/10.3991/ijoe.v12i07.5737 \\ Yiwang Wang ${ }^{1,2,3}$, Houjun Tang ${ }^{1}$, Shukai Fan ${ }^{4}$, Hai Chen ${ }^{5}$, Rui Wang ${ }^{2}$ \\ ${ }^{1}$ Shanghai Jiao Tong University, Shanghai, China. \\ ${ }^{2}$ Suzhou Vocational University, Suzhou, Jiangsu, China. \\ ${ }^{3}$ Jiangsu Engineering Research Center for PV Generation, Suzhou, Jiangsu, China \\ ${ }^{4}$ China Mobile Communications Group Shandong Co., Ltd.Jinan, Shandong, China \\ ${ }^{5}$ Suzhou Institute of Measurement and Testing Technology, Suzhou, Jiangsu China
}

\begin{abstract}
In order to meet the needs of modern intelligent agricultural detection, this paper designs and develops a novel energy-saving intelligent wireless agricultural detecting system combined with technologies green power supply, wireless transmission and digital control. This system can be powered by green energy resources such as solar energy or wind power and combined with digital control and wireless communication technologies it can achieve collection of a large amount of parameters in terms of modern agricultural cultivation, which will meet the needs of different application scenarios. Results of repeated experiments have shown that it has such advantages as being green and environmentfriendly, flexible and reliable.
\end{abstract}

Index Terms-Digital control, energy-saving, intelligent agriculture, multi-parameter, system design and development, wireless communication.

\section{INTRODUCTION}

Crop growth and yield is greatly related to environmental parameters [1]. With the development of modern technology, using new technology for real-time monitoring over crop growth can not only provide protection for agricultural fine management but also improve crop quality and reduce production costs [2]. An increase of both yield and economic efficiency can be achieved by creating optimal conditions for crop growth through measurement and due improvement of greenhouse environmental factors such as temperature, humidity, illumination and so forth [3].

In greenhouses of conventional agricultural production, power supply need to set up wires and farmland has many nodes that need to be detected. Hence, it is not suitable to use conventional AC power supply. However, using green energy resources such as solar energy, wind power, etc. can solve the big problem in terms of power supply for intelligent agricultural data collecting and monitoring.

This design uses solar photovoltaic energy, wind power and other green power to supply power to the designed data collecting system. Meanwhile, it utilizes digital control and wireless communications technologies to design and to develop a new type of energy-saving agricultural wireless intelligent detecting system, which is powered by solar or wind energy in operation and equipped with Bluetooth, wireless and other communications functions to facilitate networking and connection of the system.

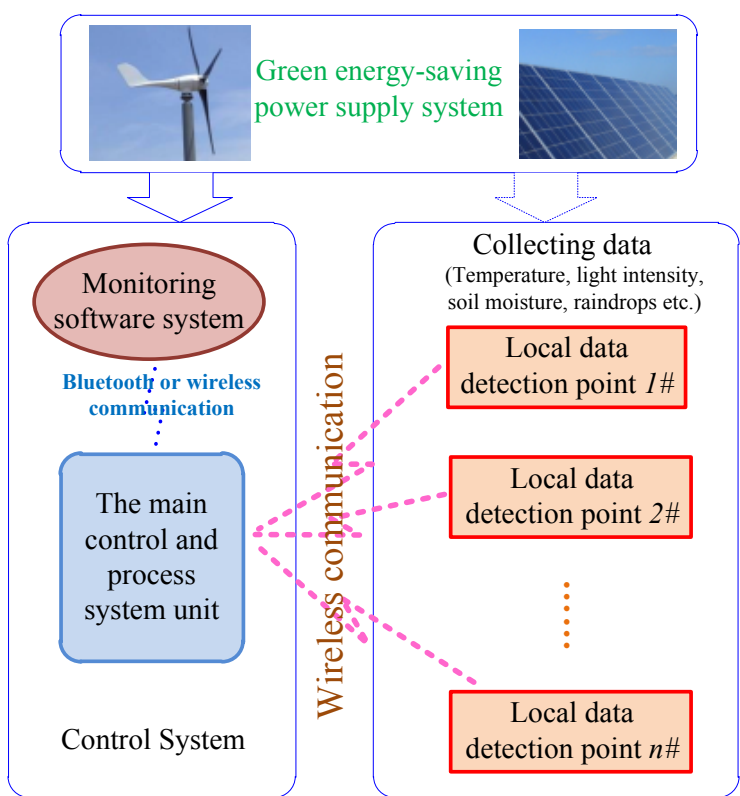

Figure 1. Block diagram of the system structure

\section{System DeSign SCHEME}

The structure of the designed system of new energysaving agricultural wireless intelligent detection is shown in Fig.1. The system consists of green-powered supply, master control unit and data acquisition component. Among them, the green power supply system supplies power to the entire system. The main control unit is responsible for collecting the detection data from the collecting unit and uploads them to the control center, where data monitoring is carried out with the help of software.

The data collecting unit is mainly to collect data from each node in site, including temperature, humidity, light intensity, raindrops and so forth. Data transmission is carried out by means of wireless communication between the data collecting and the main control unit while that is carried out by way of Bluetooth or wireless communication between the main control unit and monitoring software.

\section{DESIGN OF CIRCUITRY OF GREEN AND ENERGY-SAVING POWER SUPPLY}

Because there are some restrictions on using conventional power supply in the general field of agricultural engineer- 
ing, so unlimited solar and wind power can be an alternative for green electricity supply.

Solar and photovoltaic power is all new green renewable energy resources, but their use is largely influenced by environmental conditions and thus has certain volatility. For agricultural data collecting, different using modes can be adopted according to the conditions in different regions. For areas with better light conditions, separate photovoltaic power generation can be selected [4]; for areas with better wind resources, wind power supply can be chosen. In order to improve the stability and reliability of power supply, the above-mentioned two ways can be adopted in complementation. The structure of solar or wind power supply system is shown in Fig.2.

After the green electricity generated by solar and wind is transmitted via the control circuit, it will be stored in the storage circuit and then by the discharge circuit will discharge electricity to supply power to the entire data collection system.

Charge-discharge circuits are mainly DC/DC conversion ones. Depending on the supply voltage and requirements of the system, different conversion circuit topologies may be used and a dedicated control chip or digital control circuit can be used as well.

\section{System HaRdWARE DESIGN}

System hardware in the design is mainly divided into two parts, namely a main controller and data acquisition nodes. The former can connect to several sub-nodes to collect detecting data.

\section{A. Controller chips}

The main controller selects STM32F103 and the node controller selects STC89C52. The former is set to fulfill wireless data acquisition, upload, display and other functions. Its block diagram is shown in Fig.3.

Microprocessor STM32F103ZET6 [5] is a 32 Coretex-M3 core processor with an operating frequency at 72 MHz. It has a built-in high-speed memory and a wealth of enhanced GPIO ports that can be achieve data transmission between peripherals and memories in high-speed. The designed minimum system circuit of the main control chip is shown in Fig.4.

The node controller is mainly to collect data and parameters including temperature, light intensity, soil moisture, raindrops, etc. and then to send them back to the host controller through a wireless path. The designed minimum system circuit of the node controller is shown in Fig.5.

The node controller uses STC89S52RC microcontroller [6] as the main control chip and its node controller minimum system circuit is shown in Fig.6.

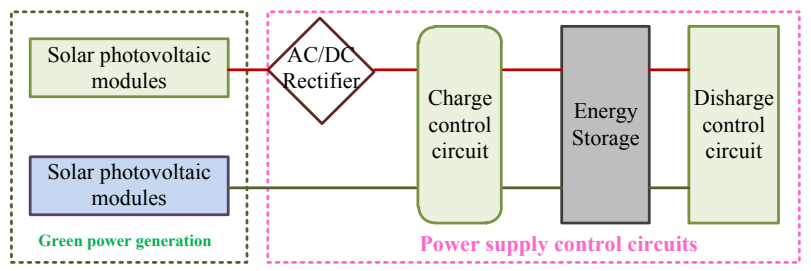

Figure 2. Green power supply system

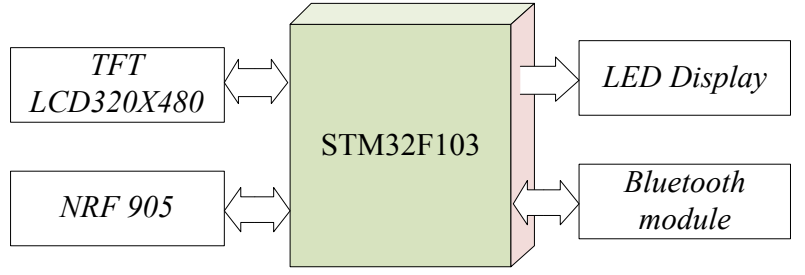

Figure 3. Block diagram of the main control circuit

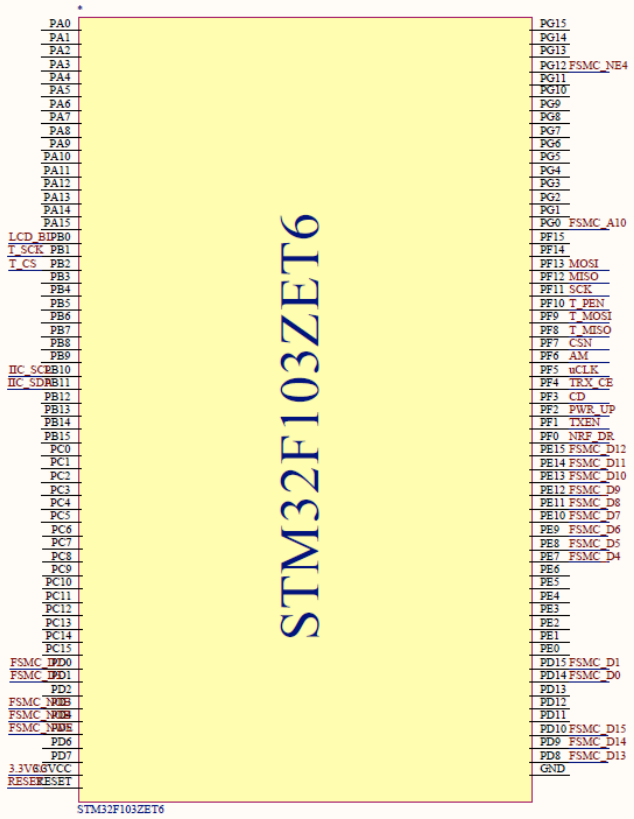

Figure 4. Minimum system circuit of the main controller

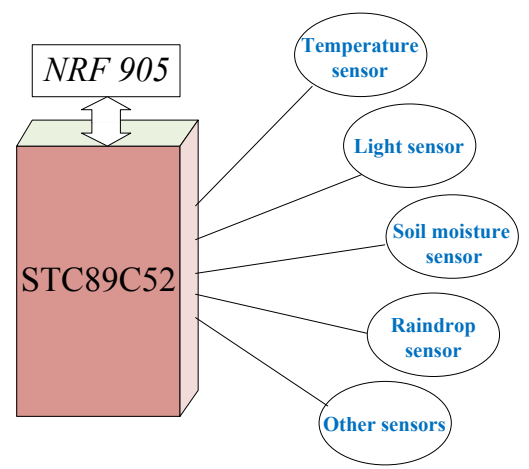

Figure 5. Schematic of node control circuit

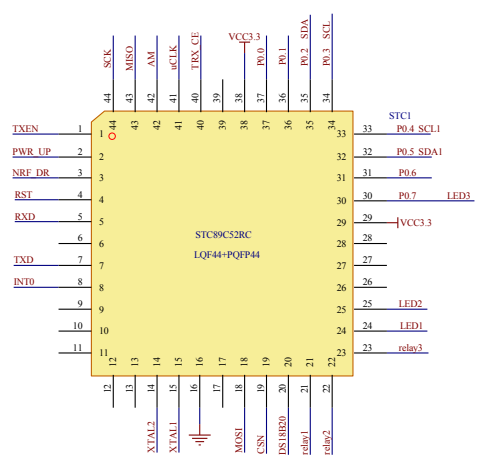

Figure 6. Minimum system of the node controller 


\section{B. Sensor curcuit design}

The temperature sensor selects DS1820 - a digital temperature sensor of single-bus system produced by DALLAS Company in the US, which can not only provide binary 9 temperature information with a resolution of $0.5^{\circ} \mathrm{C}$ but also measure the temperature within the range of $-55 \sim+125^{\circ} \mathrm{C}$ [7]. The temperature sensor connection circuit is shown in Fig.6, which enables single-bus communication with the microcontroller for reading digital temperature value.

Light sensor, which can read the light intensity data in real time, selects the digital type of BH1750FVI and it uses an I2C interface to connect to the node controller [8]. The light sensor connection circuit is shown in Fig.7.

The AD data acquisition circuit uses a dedicated chip PCF8591 [9] to achieve related data acquisition, which can read multiple $\mathrm{AD}$ data input. The schematic of PCF8591 circuit is shown in Fig. 9. The soil moisture, raindrops and $\mathrm{CO}_{2}$ sensors will switch signals collected by the dedicated AD chip into voltage ones.

Wireless communication is enabled between the main and the node controller based on nRF905 wireless communication interface circuit [10], as shown in Fig.10. Wireless transceiver board is composed of nRF905 chips and discrete components [11]. Thus, it can meet the communication requirements of environmental parameters acquisition.

\section{Other circuit design}

The control node provides relay output control circuit that can automatically control external devices. It can be connected to related equipment including ventilation, heating devices and so forth to achieve the automated control of modern intelligent agriculture.

The schematic of communication and power LED indicator circuit is shown in Fig.12, which can indicate the working status of the power and wireless communication.

\section{SOFTWARE DESIGN}

The system software is divided into controller software and PC monitoring software. The controller software includes that of the main controller and that of the node controller. The diagram of the total software configuration is shown in Fig.13, wherein the controller software is programmed in $\mathrm{C}$ language and the $\mathrm{PC}$ software in $\mathrm{C \#}$ language.

The main programming flow chart of the main controller system is shown in Fig.14. After the initialization of the controller system, a process of data collecting is carried out to achieve the acquisition of various parameters. Subsequently, the collected data is identified as whether exceeds the set limit. If exceeded, the program will go to alarm handling. Finally, the data display will be updated as a result.

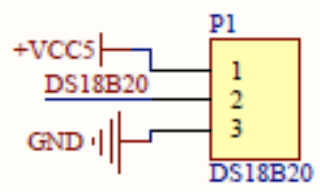

Figure 7. Schematic of the temperature sensor connection circuit

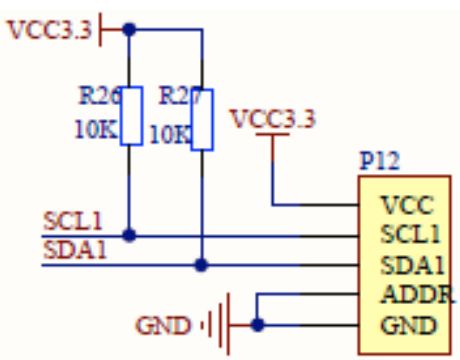

Figure 8. Diagram of the Light Sensor Connection Circuit

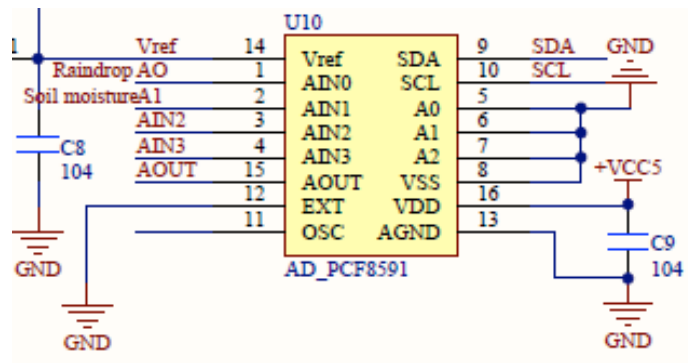

Figure 9. Schematic of $\mathrm{AD}$ data acquisition circuit

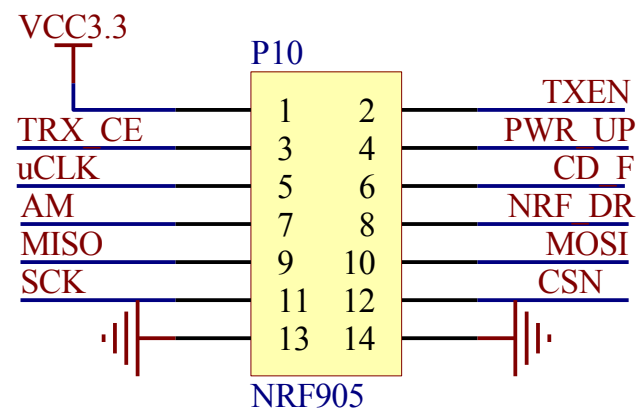

Figure 10. Schematic of nRF905 wireless communication interface circuit

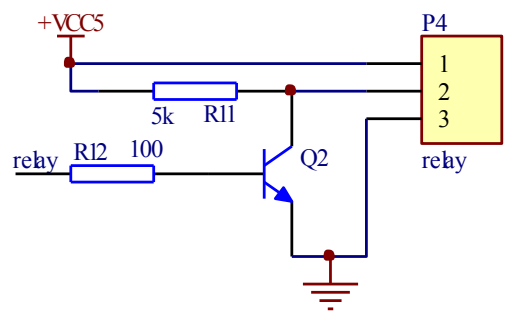

Figure 11. Schematic of the relay output control circuit

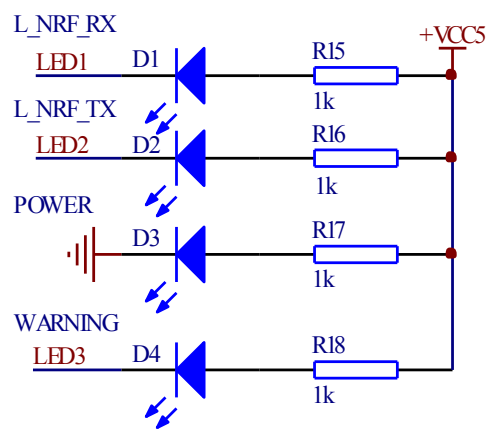

Figure 12. Schematic of the LED indicator circuit 
The main monitoring interface includes menu settings area, communication settings, real-time data collection and processing, display interface and control output switches. Each monitoring parameter can be set via the menu area. The PC monitoring software interface is shown in Fig.15.

\section{SYSTEM EXPERIMENTAL TEST}

In order to verify the feasibility and performance of the system, this research has designed and developed an experimental prototype system for testing experiments. The prototype system is shown in Fig. 16.

The prototype system includes one photovoltaic module (power supply system), three node controllers and one main controller (main control system).

The experimental test picture of prototype system is shown in Fig.12. The main controller can receive information from control node of environmental parameter and has it displayed on the TFT screen. Simultaneously, the parameters of node operation can be set by the master node.

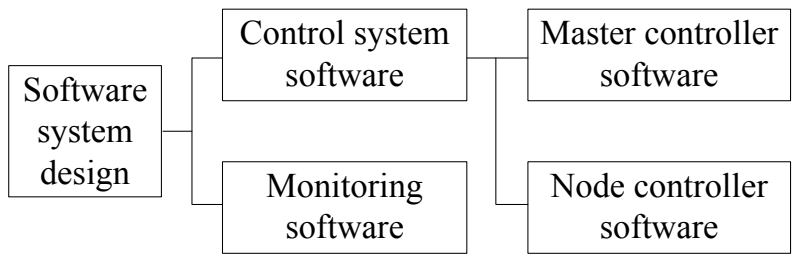

Figure 13. Software System Composition

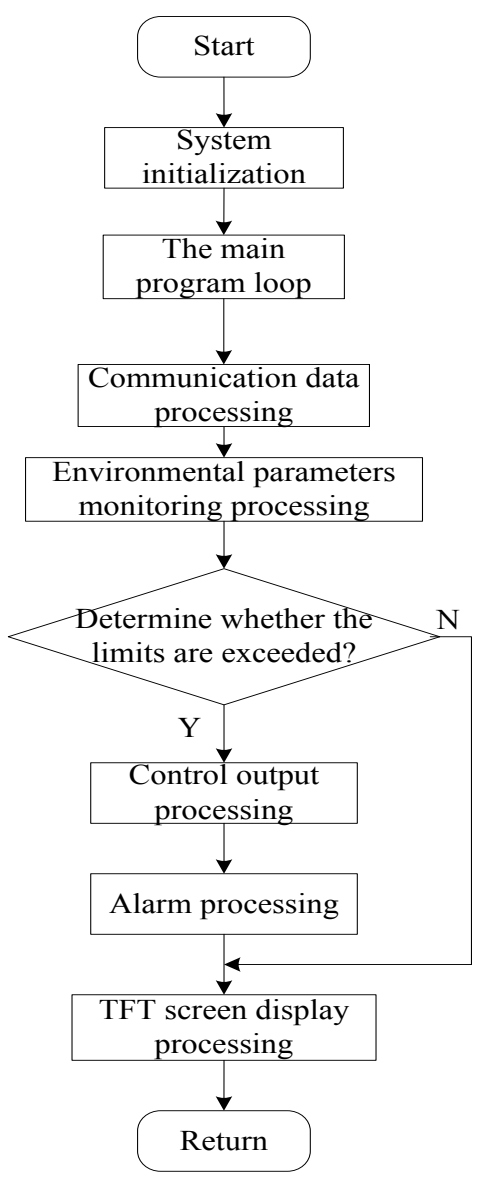

Figure 14. Main programming flow chart of the master controller system
Wireless communication is enabled between the main controller and the nodes, which can provide convenient and flexible arrangement of position for each node.

The PC monitoring interface is shown in Fig.18. Data from each node is collected and processed by the computer and displayed real-time. The host and the main controller can also communicate with each other through Bluetooth or Wi-fi.

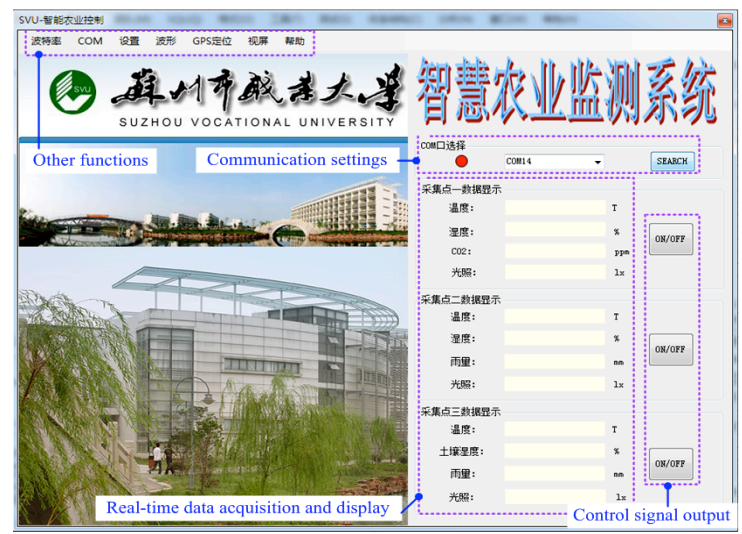

Figure 15. Main monitoring system interface

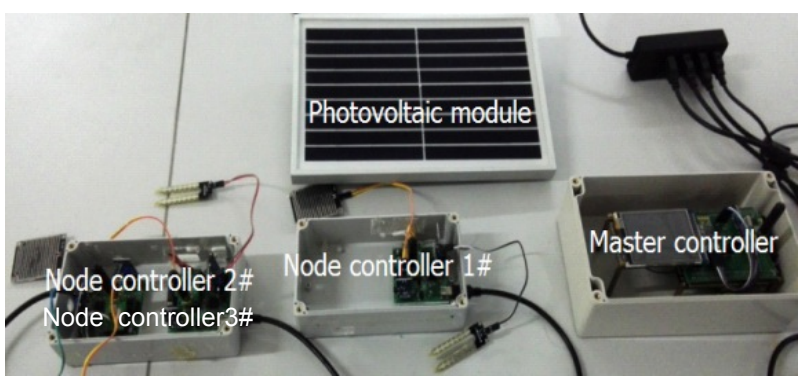

Figure 16. The prototype system

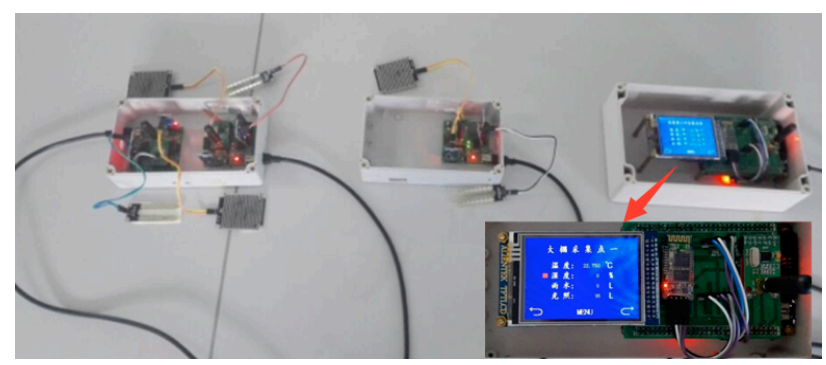

Figure 17. Experimental test picture

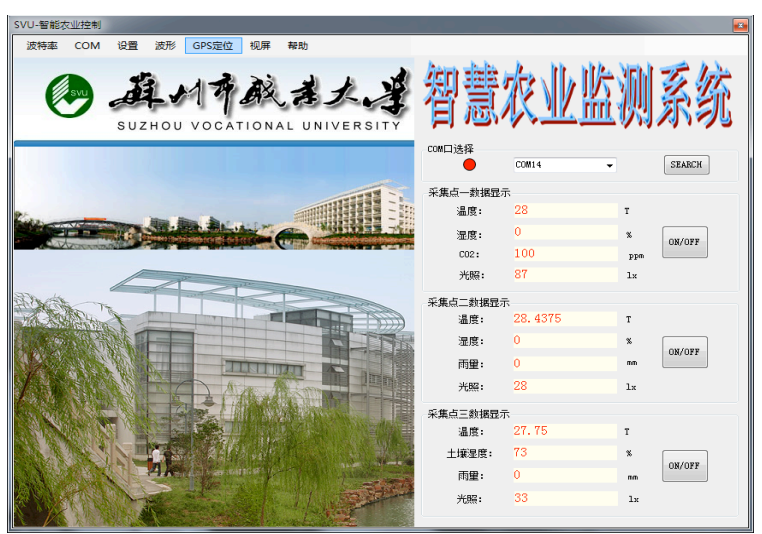

Figure 18. Main interface of experimental test monitoring 


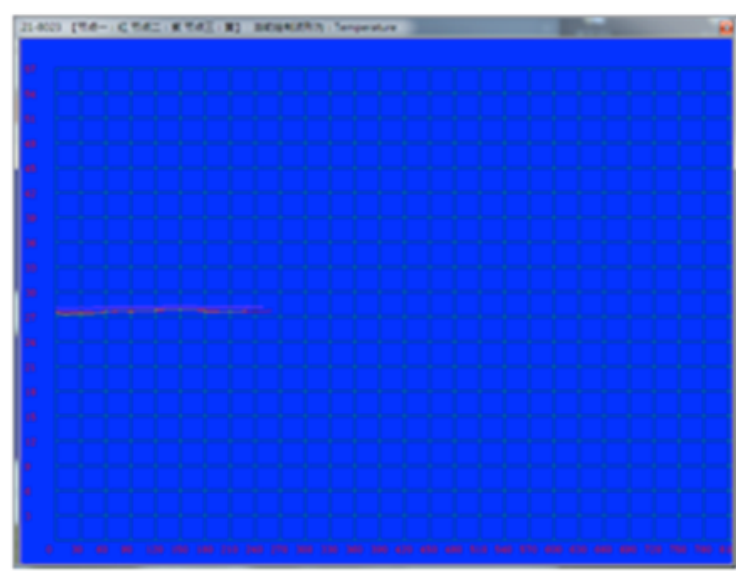

(a) Node's temperature curve

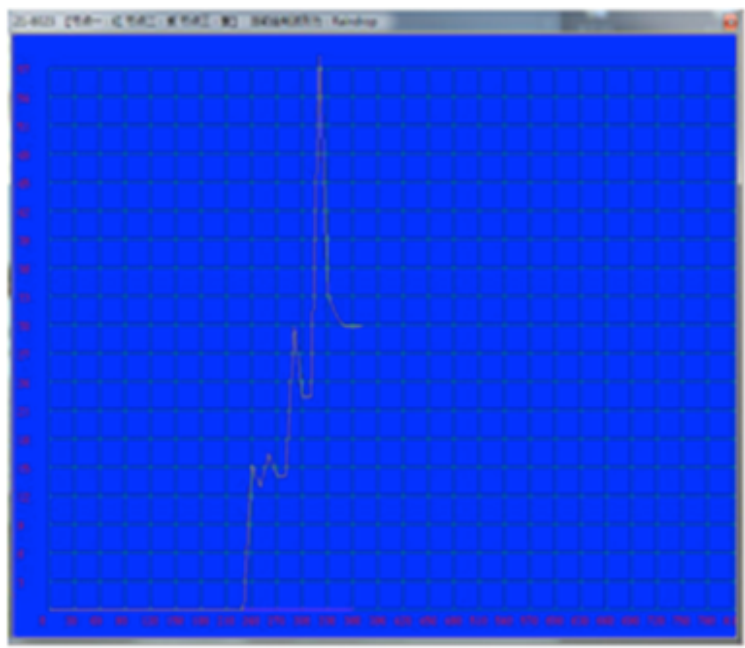

(b) Node's raindrop curve

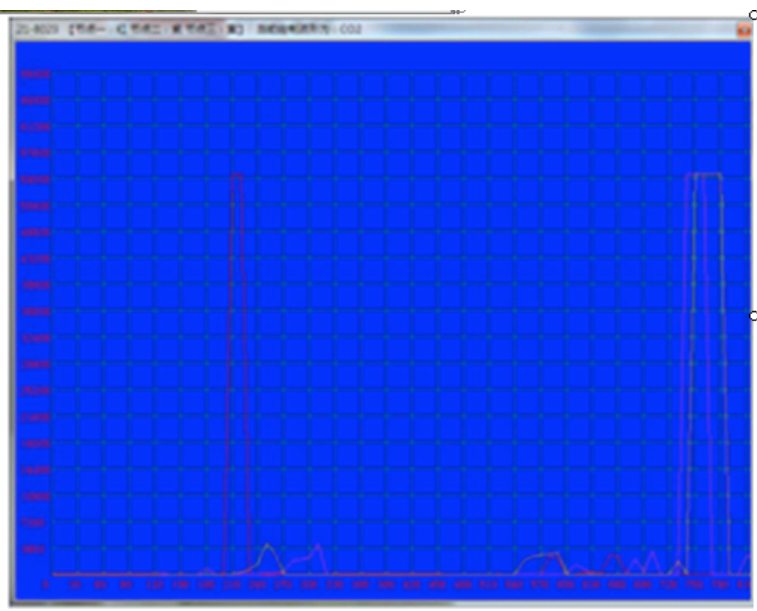

(c) Node's $\mathrm{CO}_{2}$ curve

The system has gone through many times of experimenting and the due experimental results have been recorded, among which the data of one case is shown in Fig. 19.

As can be seen from the results of the repeated experiments, the system can complete the task of data acquisition and achieve the intended design goals. Therefore, it is suitable to be applied and promoted in the field of agricultural data collection.

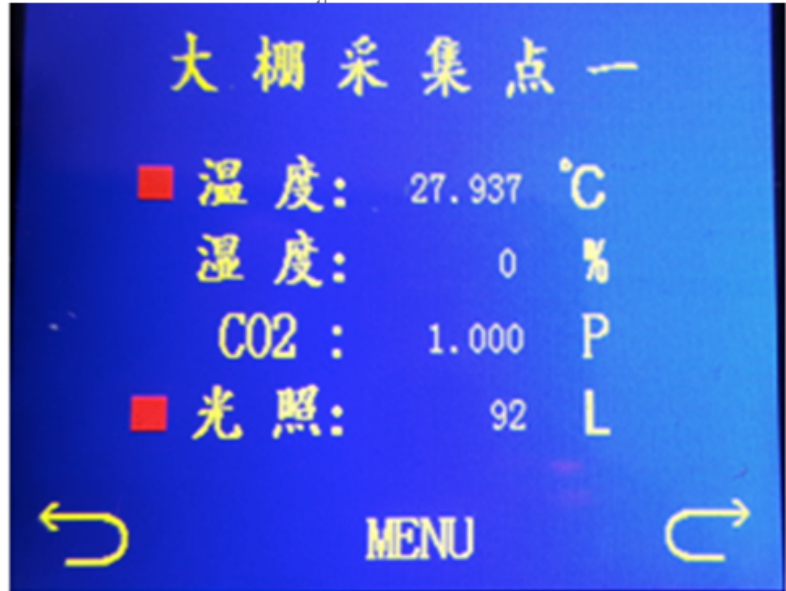

(d) The No.1 node controller display interface

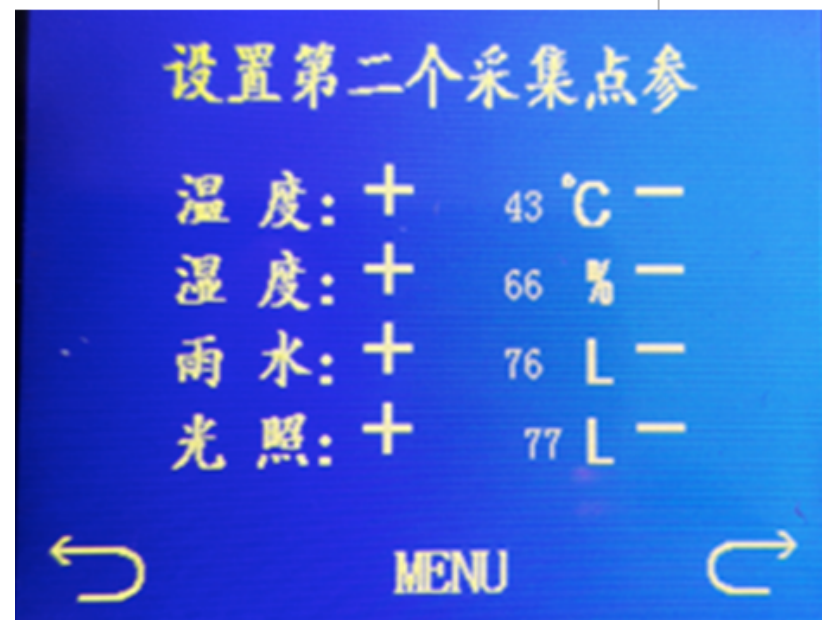

(e) The No.2 node controller setting interface

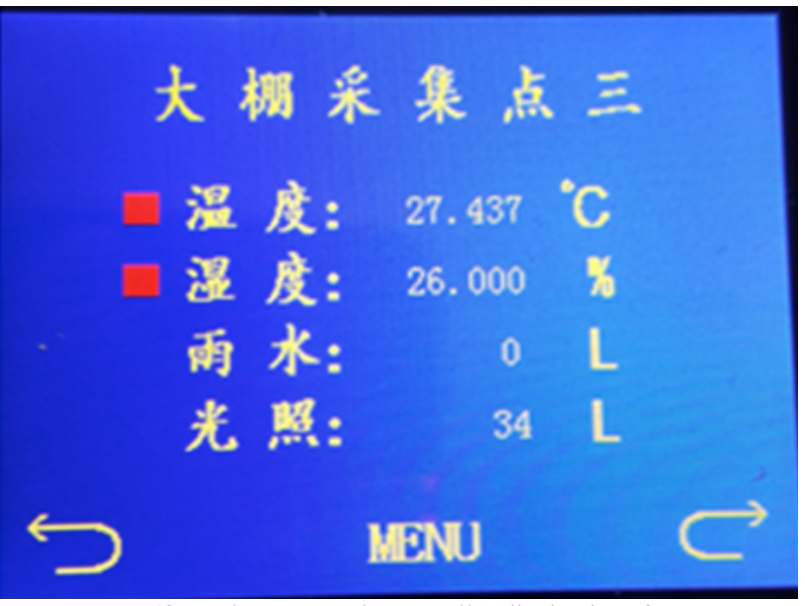

(f) The No.3 node controller display interface

Figure 19. Some experimental test results

\section{CONCLUSION}

In this paper, the design has applied brought solar/wind or other green power to the agricultural data collection system to supply green power for intelligent agriculture. This paper has first resolved the detection problem of the conventional monitoring system with the help of digital control and wireless communication technologies. Then, it has designed and developed a novel system of intelligent agricultural data collecting, which is both energy-saving and based on wireless communication. Finally, an experimental prototype has been developed to test the reliability 
and feasibility of the system. Through repeated experiments, the results have shown that the designed system, as is green, flexible and reliable, is suitable be applied and promoted in the field of agricultural data collection.

\section{ACKNOWLEDGMENT}

The authors wish to acknowledge the financial support through Qing Lan Project, University Scientific Research and Industry Promotion Project of Jiangsu Province, Science and Technology Construction System Project of Jiangsu Province, Science and Technology Planning Project of Suzhou City and Science and Technology Planning Project of Wuzhong District of Suzhou City, and Foundation of Suzhou Vocational University.

\section{REFERENCES}

[1] GAO L-A., LI Y-L., ZHAO M. Design of wireless greenhouse monitoring system based on ZigBee and GPRS. Agriculture Network Information 2013, issue 10, pp.30-32.

[2] YU B-K., HU Y. Application of GIS and ZigBee technology in the monitoring system of agricultural greenhouse. Hubei Agricultural Sciences 2014, Vol. 53, Issue 1, pp.211-215

[3] ZHANGY-C., YANGY-F., YE X-L., YANG L. Design of communication for greenhouse monitoring system based on CAN Bus. Control Engineering of China 2009, Vol. 16, Issue 1, pp. 103-106.

[4] YAN F-F., ZHANG S-G., SUO X-S., CHENG M., GAO L-A. The design of solar-powered agricultural greenhouse nodes' data acquisition system. Journal of Agricultural Mechanization Research 2013, Issue 5, pp.103-105.

[5] STMIROELECTRCNICS.STM32F103XE Data sheet. Geneva: STMICROELECTRONICS 2010.

[6] http://www.stcmcu.com/

[7] HUANG P., WANG J-J. Principle of the DS1820 temperature sensor and its application. Instrument Technique and Sensor 2001, Issue, pp.29-31.

[8] YUN Z-H., BAI T-R. Indoor light intensity measuring instrument based on BH1750FV1. Microcontrollers \& Embedded Systems 2012, Issue 6, pp.27-29.

[9] ZHOU J-L., GUO J-B., CUI T. The used of A/D chip PCF8591 which has $\mathrm{I}^{2} \mathrm{C}$ interface. Control \& Automation 2005, Vol. 21, Issue 7, pp.150-151.

[10] CHEN D-Y., SI Y-J., AI S-F., JIN J-L., SI Y-G. Design of a multi-point data acquisition system based on MSP430 and nRF905. Telecommunication Engineering 2013, Vol. 53, Issue 10, pp.1384-1388.

[11] HU J., ZHANG J-B., ZHAO Z-J., GUO H. Design of greenhouse intelligent machine control system based on nRF905 wireless chip. Journal of Chinese Agricultural Mechanization 2015Vol. 36, Issue 3, pp.118-122.

[12] CHENG M., YUAN H-B., GAO L-A. Greenhouse wireless sensor network precise monitoring system based on solar power supplying. Guangdong Agricultural Sciences 2013, Issue 3, pp.179-181.
[13] TIAN F-M., YI S-J., TAN F., WANG X-L., HAN D-L., SHI J-F. Design of a universal acquisition controller using power supplied by solar energy for rice seedling greenhouse in cold area of northeastern China. Guangdong Agricultural Sciences 2013, Issue 5, pp.191-194.

[14] CHEN Y-A., JIN Y-A. Review of control technologies for windsolar hybrid generation system. Electric Drive 2012, Vol. 42, Issue 1, pp.3-9.

[15] LI L-Y., WANG Z-X., ZOU J-L. Design of human-machineinterface system applying to mobile emergency lighting power supply based on STM32F103ZET6. Chinese Journal of Power Sources 2014, Vol. 38, Issue 4, pp.697-699.

[16] ZHANG X., CHEN L-S., ZHAO J. Design and application of intelligent agricultural greenhouse based on Internet of things technology. Journal of Chinese Agricultural Mechanization 2015, Vol. 36, Issue 5, pp.90-95.

[17] LIU C-H., ZHANG M., ZHANG F., LIU G. Development of agricultural information processing platform based on wireless sensor networks. Journal of China Agricultural University 2011, Vol. 16, Issue 5, pp.151-156.

[18] SHI L-M., CHEN Z-F., GAI Z-H. Application research of the Internet of things in wisdom agriculture. Journal of Agricultural Mechanization Research 2013, Issue 6, pp.250-252.

[19] REN X-H., FU C-H., HU K. Wireless data acquisition system design based on Bluetooth technology. Measurement \& Control Technology 2009, Vol. 28, Issue 1, pp.16-19.

[20] QU W-Y., HU C-K. Plant leaf color and ecological environment parameters of a wireless data acquisition system. Journal of Northwest Ag\&F University (Nat. Sci. Ed.) 2012, Vol. 40, Issue 7, pp.221-228.

\section{AUTHORS}

Yiwang Wang (corresponding author) is with the Department of Electrical Engineering, Shanghai Jiao Tong University, Shanghai 200240, China and School of Electronic \& Information Engineering, Suzhou Vocational University, Suzhou 215104, Jiangsu, China and Jiangsu Engineering Research Center for PV Generation, Suzhou 215104, Jiangsu, China (e-mail: wyiwang@163.com).

Houjun Tang is with the Department of Electrical Engineering, Shanghai Jiao Tong University, Shanghai 200240, China.

Shukai Fan is with the China Mobile Communications Group Shandong Co., Ltd.Jinan 250001, Shandong, China.

Hai Chen is with Suzhou Institute of Measurement and Testing Technology,Suzhou 215128,Jiangsu China.

Rui Wang is with the School of Electronic \& Information Engineering, Suzhou Vocational University, Suzhou 215104, Jiangsu, China. 